\title{
The orthograde flow of tritiated proline in corticospinal neurons at various ages and after spinal cord injury
}

\author{
EARL R FERINGA, H LEE VAHLSING, RC DAUSER \\ From the VA Medical Center, San Diego, California and Ann Arbor, Michigan, and the Department of \\ Neurosciences, University of California, San Diego, USA
}

SUMMARY The amount of radioactive proline which reaches the cervical cord by axoplasmic flow after intracortical injection of label is higher in rapidly growing 3 to 6 week old rats but becomes relatively constant in unoperated control rats beyond age 10 weeks. In adult rats with spinal cord transection at T-8, however, the amount of tritiated proline detected in the cervical cord above the site of transection is markedly increased five weeks after surgery, falls to more normal levels by 14 weeks after surgery, and is significantly below normal at 25 weeks after surgery. These findings are consistent with abortive attempts to regenerate axons at five weeks after injury. Twenty-five weeks after injury neuronal death and loss of both cells and axons which would normally project to the caudal cord through the site of spinal cord transection result in a decrease in the axon label found in the cervical region. Recognition of this variability in the amount of radioactivity that reaches the cervical region after spinal cord injury forced a reconsideration of previously reported evidence ${ }^{1}$ for regeneration in spinal cord transected animals receiving no specific postoperative therapy. There is no evidence for regeneration in such untreated transected rats.

In several recent publications, we have reported studies of the axoplasmic flow of tritiated proline in the corticospinal tract after injection of a small amount of high specific activity tritiated proline into the appropriate sensory-motor cortex area in the rat. The amount of label in the corticospinal tract was used as a measure of corticospinal tract regeneration after spinal cord transection. ${ }^{1-3}$ Observations included a claim that some regeneration occurred in untreated control animals as measured by this criteria.' $^{\prime}$

More recently, we have focused our attention on the neuronal cell body after spinal cord transection and have discovered cell death of neurons in the fifth layer of the sensory-motor cortex following spinal cord transection. ${ }^{45}$ This cell death does not occur immediately but peaks at approximately ten weeks after a spinal cord transection which causes axotomy of the neurons.

Address for reprint requests: Earl R Feringa, M.D., Neurology Service (127), VA Medical Center, 3350 La Jolla Village Drive, San Diego, CA 92161, USA

Received 14 February 1984. Accepted 17 March 1984
This paper details the changes that occur after spinal cord transection in the amount of tritiated proline found labelling cervical corticospinal tracts 21 days after intracortical injection of labelled proline. These changes make it necessary to reevaluate our previously reported findings. While strengthening the interpretation that one intervention reported in our earlier experiments did allow a few axons to regenerate, they negate the interpretation that some regeneration of corticospinal tracts occurs in untreated control animals.

\section{Materials and methods}

We used rats from our own inbred colony. They were originally developed from a Wistar strain but have been brother and sister mated for more than 80 generations and have been demonstrated to be isogeneic.

Surgery

Animals were anaesthetised and a dorsal laminectomy was done at spinal level T-6/T-7. The spinal cord was exposed (T-8 cord level) and completely transected along with its dural coverings. The completeness of spinal cord transection was always confirmed visually by two investigators 


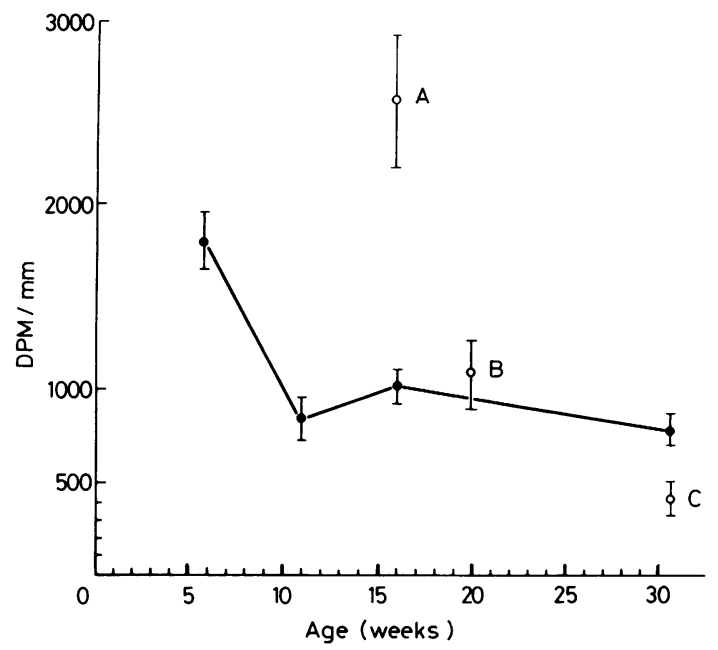

Fig Tritiated proline detected in the cervical spinal cord of normal and untreated spinal cord transected rats at various ages and at various times after spinal cord transection. The solid dots and line indicate DPM/mm cervical cord in rats injected with $50 \mu \mathrm{C}$ tritiated proline into each cerebral cortex motor/sensory area. Rats were injected 21 days prior to study. Very young (injected at 3 weeks studied at 6 weeks) rats have high DPM, probably reflecting continued active growth. From 11 to 31 weeks of age cervical DPM are quite constant at $878 \pm 58(\bar{x} \pm S E M)$. Point $A$ represents cervical counts of rats transected as adults, injected 2 weeks after transection, and studied 3 weeks later. The increased activity may reflect efforts at axonal regeneration after transection. Point $B$ represents adult transected rats studied 14 weeks after transection. Point $C$ represents $D P M / \mathrm{mm}$ cervical cord in adult rats transected 25 weeks prior to study. The decreased activity is consistent with cell death of corticospinal neurons deprived of a target tissue.

using the operating microscope. Postoperatively the animals received careful nursing care, including the expression of urine by the method of Credé, every eight hours during the first two weeks. Once automatic bladders were established, the animals were observed daily, but required no specific intervention except for rare occasions when infections occurred.

\section{Labelling with tritiated proline}

A burr hole was placed with a dental drill under constant stream of cool saline directly over the area of the sensory-motor cortex. ${ }^{6}$ Using a 32 gauge short bevelled needle, we injected $2.5 \mu$ l of lactated Ringer's solution containing $50 \mu \mathrm{C}$ of tritiated proline into the cerebral cortex $1 \mathrm{~mm}$ below the cortical surface. The proline was injected very slowly over a period of one-half to one minute. The needle was then allowed to stay in place for an additional minute before it was slowly withdrawn. A similar injection was performed into each hemisphere.

After injection of tritiated proline, 21 days were allowed for complete labelling of the corticospinal tract. ${ }^{3}$ We have previously demonstrated that this procedure labels the cor- ticospinal tract and no other areas in the spinal cord. ${ }^{3}$ On the day when the animals were to be killed, they were anaesthetised and perfused with physiological saline followed by $10 \%$ formalin. A measured length of spinal cord was taken from the cervical region at a distance cranial enough from the transection site to assure that neither the site of transection nor the resultant post-traumatic cyst were involved in the area of tissue studied. The segments were solubilised and scintillation-counted for tritium. The number of disintegrations per minute (DPM) per millimeter cord length was determined. Each group of animals included animals with spinal cord transection and age/sex matched animals without spinal cord transection.

\section{Results}

The graph (fig) shows the number of DPM per millimeter length of spinal cord in animals with and without spinal cord transection. The amount of tritiated proline found in the cervical cord of intact rats is quite constant in adults, including those studied at 11,16 and 31 weeks of age. The youngest group (injected at age 3 weeks and studied at age 6 weeks) has a much higher DPM in the cervical region than that found in the adults.

Five weeks after spinal cord transection in adult animals, there was a marked increase in the DPM detected in the cervical segment (fig, point A). For animals studied 14 weeks after transection that number decreased and was near that expected in intact rats of the same age (fig, point B). Animals in which the tritiated proline was injected 22 weeks after spinal cord transection and which were perfused 25 weeks after spinal cord transection (fig,

Table 1 Comparison of cervical spinal cord DPM 3 weeks after intracortical injection of $50 \mu \mathrm{C}$ of tritiated proline into each motor cortex. In these animals only the corticospinal tract is labelled in the cervical cord, therefore, DPM is a reflection of tritiated proline transported by axoplasmic flow in the corticospinal tract. Spinal cord transected (untreated) rats are compared to intact rats. Rats studied as adults (14-31 weeks of age) showed cervical counts of $878 \pm 58$. Five weeks after spinal transection the cervical DPM's are greatly increased, perhaps reflecting an effort at regeneration of corticospinal tracts. By 25 weeks after transection, the cervical DPM is significantly decreased reflecting the decrease in surviving corticsopinal axons (cells).

\begin{tabular}{llll}
\hline & \multicolumn{4}{l}{ Weeks after spinal cord transection } \\
\cline { 2 - 4 } & 5 & 14 & 25 \\
\hline $\begin{array}{c}\text { Expected cervical } \\
\text { DPM (from pooled } \\
\text { normal adult rats) }\end{array}$ & $\longleftarrow 878 \pm 58$ & \\
$\begin{array}{c}\text { Observed cervical } \\
\text { DPM (from } \\
\text { transected adult rats) }\end{array}$ & $2704 \pm 374$ & $1051 \pm 185$ & $415 \pm 93$ \\
& $\begin{array}{l}<0.005 \\
\text { increase }\end{array}$ & NS & $\begin{array}{c}<0.005 \\
\text { decrease }\end{array}$ \\
\hline
\end{tabular}


Table 2 Effects of treatment on axoplasmic transport of tritiated proline to the cervical and lumbar cord of rats with a complete spinal cord transection at T-8. Note increased DPM in cervical region at 5 weeks postoperative $(p<0.005)$; probably a reflection of increased flow of axoplasmic protein in an attempt to regenerate. Also note increase in the lumbar area DPM only in those rats made immunologically tolerant and immunosuppressed with cyclophosphamide $(p<0 \cdot 025)$ reflecting some success at regenerating axons across the transection site.

\begin{tabular}{llccc}
\hline Treatment group & $\begin{array}{l}\text { Age at spinal cord } \\
\text { transection }\end{array}$ & $\begin{array}{l}\text { Time after spinal cord } \\
\text { transection }\end{array}$ & DPM cervical & DPM lumbar \\
\hline Control & $11-15$ & $5 \mathrm{wks}$ & $2704 \pm 374$ & $44 \pm 12$ \\
Control & 6 & $14 \mathrm{wks}$ & $1051 \pm 185$ & $51 \pm 6$ \\
Immunotolerant & 6 & $14 \mathrm{wks}$ & $1004 \pm 181$ & $46 \pm 7$ \\
$\begin{array}{l}\text { Immunotolerant and } \\
\text { immunosuppressed }\end{array}$ & 6 & $14 \mathrm{wks}$ & $883 \pm 215$ & $161 \pm 100$ \\
\hline
\end{tabular}

point C) showed a significantly $(p<0.005)$ decreased amount of tritiated proline in the corticospinal tracts of the cervical region as compared with age/sex matched control animals without spinal cord transection. Table 1 displays the DPM which would be expected in the cervical cord of unoperated adults and the observed DPM in animals with a previous spinal cord transection.

\section{Discussion}

Intact (non-transected spinal cord) rats studied at 6 weeks of age had been injected at age 3 weeks. This period is one of rapid body growth. We feel the increased label found in the cervical region of these rats reflects the rapid body growth and accompanying growth and elongation of spinal axons.

Our rats are sexually mature at age 6-7 weeks and we, therefore, call them "adult". Like all rats, they continually grow during their life span and never reach a static body size. After age 6 weeks, however, the rats' growth slows considerably. This experiment shows that axonal label with cortically injected tritium also becomes more constant. No significant differences are found between intact rats studied at age 11,16 or 31 weeks. In these rats, cervical DPM $=878 \pm 58(\bar{x} \pm$ SEM $)$.

Changes occur in the corticospinal tract of the rat after spinal cord transection. At 5 weeks after operation, the proximal axons have more label of tritiated proline (table 1), presumably due not to an increased number of axons but rather to an increased axoplasmic flow in what appears to be an effort to regenerate the amputated axon. The heavier label is significantly above $(p<0.005)$ that seen in rats without spinal cord transections.

By 25 weeks after spinal cord transection, the reverse is true. The amount of tritiated proline detected in the cervical region is less than that seen in control animals. Presumably, the corticospinal neurons are either nonfunctional or dead and, therefore, not able to transport the usual amount of triti- ated proline down the corticospinal tracts.

Our finding that these cells are not able to transport horseradish peroxidase (HRP) in the retrograde direction, ${ }^{4}$ and our finding that there is evidence of dying corticospinal neurons at ten weeks after spinal cord transection, ${ }^{5}$ lead us to speculate that this decrease in tritiated proline detected in the cervical segment is secondary to cortical cell death following spinal cord transection.

These results have an important bearing on our earlier reports of evidence for regeneration, particularly our misinterpretation that there had been some regeneration in untreated control animals. ${ }^{2}$ In that experiment, we labelled the corticospinal tract of 20 week old rats 14 weeks after spinal cord transection following the above protocol. As a measure of corticospinal tract regeneration across the transection site, we expressed the DPM/mm found in a caudal segment taken distal to the transection site as a percentage of the DPM/mm found in a cervical segment taken proximal to the site. Percentages rather than DPM were compared to compensate for different degrees of success in labelling the corticospinal tract. Treatments which permitted some corticospinal tract regeneration were expected to transmit a higher percentage of tritiated proline across the transection site than untreated controls would. We found $13 \%$ transport in our immunotolerant and suppressed group compared with $7 \%$ in the controls $(\mathrm{p}<0.04)$.

To determine a background percentage which would represent tritium transported to the caudal segments by means other than axoplasmic flow in the corticospinal tract, we tritium labelled "short term controls" in an identical fashion. These adult animals were killed five weeks later, an interval we considered too short for any regeneration to have occurred. Therefore, any tritium present in their caudal segments was considered background. About $2 \%$ of the cervical cord tritium label was found in the spinal cord segment below the transection site. This was designated background.

The fact that the 14 week control animals trans- 
mitted $7 \%$ tritium while the short term controls transmitted only $2 \%(p<0 \cdot 001)$ led us to conclude that some regeneration occurred even in the untreated 14 week control animals. After examining the orthograde axoplasmic transport of tritium to the cervical spinal cord after mid-thoracic spinal cord transection reported in this paper, we realise the source of this incorrect conclusion.

At five weeks after spinal cord transection, the labelling of the cervical cord is greatly elevated over that found at 14 weeks post-transection (table 2). There is no difference in the amount of tritium found below the transection site in five and 14 week controls. Hence, it was the denominators (cervical DPM) of our percentages that were different $(p<$ 0.005 ), not the numerators (caudal DPM). Therefore, there was no indication of regeneration in 14 week controls.

Similar reasoning negates the radioisotopic endpoint difference between control animals and those made immunologically unresponsive to CNS tissue as the only treatment received. That group, compared to proper controls, shows no significant evidence of regeneration $(p<0 \cdot 40)$. The electrophysiologic evidence of regeneration in this group remains valid. When compared to proper controls, two of nine treated animals showed evidence for regeneration while zero of 17 controls showed such a response $(p<0.05)$.

The difference reported between rats made immunotolerant to CNS antigens and suppressed with cyclophosphamide as compared to their appropriate age/sex matched control animals is significant $(p<0 \cdot 04)$. In these animals the differences were not in the counts detected in the cervical region, which were practically identical, but rather in the counts detected in the low thoracic/lumbar area below the area of transection (table 2). These animals were the same age. Each had a complete spinal transection at an identical location. The only difference in the raw data is found in the lumbar counts. The treatment with induced immunotolerance plus cyclophosphamide is successful in allowing a few axons to regenerate as measured by axoplasmic flow of tritiated proline injected into cortical regions.

\section{References}

${ }^{1}$ Feringa ER, Nelson KR, Vahlsing HL, Dauser RC. Spinal cord regeneration in rats made immunologically unresponsive to CNS antigens. $J$ Neurol Neurosurg Psychiatry 1979;42:642-8.

${ }^{2}$ Feringa ER, Shuer LM, Vahlsing HL, Davis SW. Regeneration of corticospinal axons in the rat. Ann Neurol 1977;2:315-21.

${ }^{3}$ Vahlsing HL, Hirschl RB, Feringa ER. Axoplasmic flow of tritiated proline in the corticospinal tract of the rat. Cell Tissue Res 1981;214:278-87.

${ }^{4}$ Feringa ER, Vahlsing HL, Smith BE. Retrograde transport in corticospinal neurons after spinal cord transection. Neurology (NY) 1983;33:478-82.

${ }^{5}$ Feringa ER, Gilbertie WJ, Vahlsing HL. Histologic evidence for death of cortical neurons after spinal cord transection. Neurology (NY) (in press).

${ }^{6}$ Hicks SP, D'Amato CJ. Motor-sensory cortexcorticospinal system and developing locomotion and placing in rats. Am J Anat 1975; 143:1-42. 